\title{
Short communication: Persistent contamination by Listeria monocytogenes of bovine raw milk investigated by whole-genome sequencing
}

\author{
M. Ricchi, ${ }^{1 *}$ E. Scaltriti, ${ }^{2}$ G. Cammi, ${ }^{1}$ C. Garbarino, ${ }^{1}$ N. Arrigoni, ${ }^{1}$ M. Morganti, ${ }^{2}$ and S. Pongolini ${ }^{2}$ \\ ${ }^{1}$ Diagnostic Section of Piacenza, Istituto Zooprofilattico Sperimentale della Lombardia e dell'Emilia Romagna (IZSLER), Strada Faggiola 1, \\ 29027-Gariga di Podenzano, (PC), Italy \\ ${ }^{2}$ Risk Analysis and Genomic Epidemiology Unit, Istituto Zooprofilattico Sperimentale della Lombardia e dell'Emilia Romagna (IZSLER), \\ Via dei Mercati 13/A, 43126-Parma, Italy
}

\section{ABSTRACT}

Following the persistent detection of Listeria monocytogenes in raw bovine milk sold through a vending machine, the 120 lactating cows of the herd producing the milk were subjected to bacteriological investigation. A single cow with subclinical mastitis $(1.2-1.3 \times$ $10^{5}$ somatic cells $/ \mathrm{mL}$ ) and persistent L. monocytogenes excretion was detected. The cow was subjected to antimicrobial therapy, but $L$. monocytogenes excretion remained high $\left(>3.0 \times 10^{2} \mathrm{cfu} / \mathrm{mL}\right)$. Following culling of the infected cow, L. monocytogenes disappeared from the tank milk, and further isolates were recovered from the mammary parenchyma and lymph nodes of the infected cow. To investigate the clonal nature of the contamination, all isolates recovered in the study $(\mathrm{n}=13)$ were analyzed by serogroup PCR, pulsed-field gel electrophoresis, and whole-genome sequencing. Our results demonstrated the clonal nature of the contamination. All isolates belonged to lineage II, serogroup IIa, sequence type 37, clonal complex 37 and harbored some virulence determinants. This case showed that, although relatively rare, prolonged milk contamination by $L$. monocytogenes can originate from subclinical and persistently infected cows, posing a health risk to consumers.

Key words: bovine milk, Listeria monocytogenes, vendor machine, whole-genome sequencing

\section{Short Communication}

The genus Listeria encompasses 17 species. Among them, only Listeria monocytogenes (LM) is considered pathogenic to humans, although Listeria seeligeri and Listeria ivanovii have been sporadically reported to cause human infections (Gasanov et al., 2005). Listeria monocytogenes poses serious concerns because of

Received January 8, 2019.

Accepted March 20, 2019

*Corresponding author: matteo.ricchi@izsler.it its ability to cause severe and sometimes fatal disease and its widespread diffusion in the environment and in food (Gasanov et al., 2005). Listeria monocytogenes can survive in environmental niches through the production of biofilm and the activation of resistance mechanisms toward the common disinfectants (Katharios-Lanwermeyer et al., 2012; Harter et al., 2017; Lee et al., 2017) as well as its ability to withstand and grow under stressful conditions, such as low temperature and high salt concentrations (NicAogáin and O'Byrne, 2016). For these reasons, LM is recognized as one of the most important foodborne pathogens (Bergholz et al., 2018).

Even though LM is widespread in the herd environment, relatively few cases of subclinical ruminant mastitis have been reported (Gitter et al., 1980; Sharp, 1989; Fedio et al., 1990; Bourry et al., 1995; Schoder et al., 2003; Winter et al., 2004; Hunt et al., 2012). Because of the scarcity of reported cases, some authors have suggested that this kind of mastitis is rare (Fedio et al., 1990). However, the excretion of LM into milk destined for human consumption can present a serious health risk, especially if milk is consumed raw, as is sometimes the case following the recent consumer trend of eating unprocessed or minimally processed food.

In Italy, selling of bovine raw milk is permitted under specific regulatory conditions defining enhanced hygienic and microbiological standards and controls (Supplemental Table S1, https://doi.org/10.3168/ jds.2019-16267). Furthermore, the warning "boil before consumption" has to be reported at the point of sale, typically automatic vending machines. Listeria monocytogenes was detected during a routine official microbiological control of the raw milk delivered by a vending machine in Piacenza Province, Italy, on $\mathrm{Au}-$ gust 31, 2011 (ISO, 2017a). After this occurrence, the sale of milk through this machine was blocked. Further official controls on the tank milk of the supplying dairy farm were carried out on September 8 and 14, 2011; both were positive, although it was not possible to determine the number of LM with sufficient confidence (ISO, 2017b). The herd supplying the milk was then 


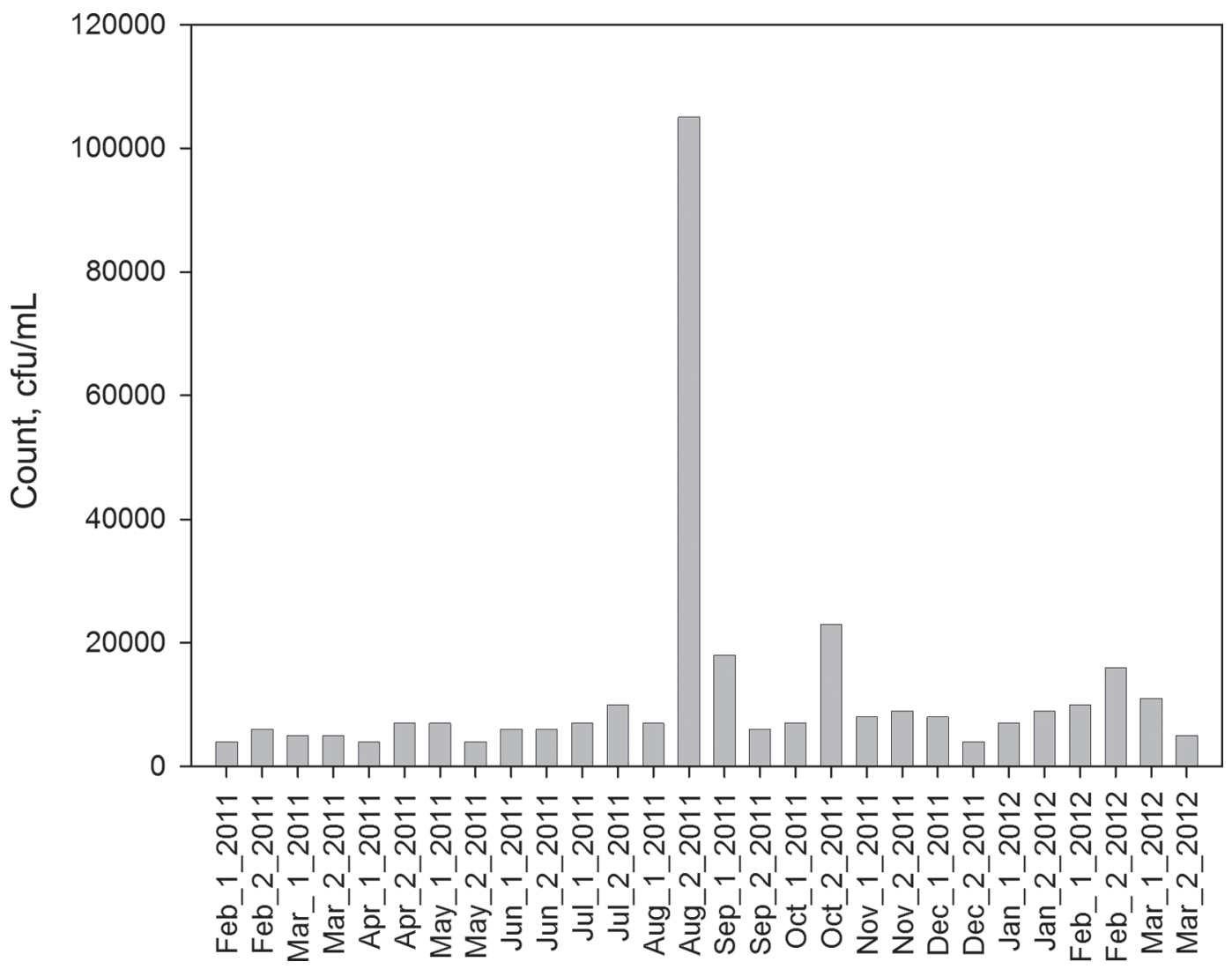

Figure 1. Total bacterial load of the tank milk from February 2011 until March 2012. The tank was sampled twice per month. Month_1_ yyyy and Month_2_yyyy refer to sampling carried out in the first and second half of each month, respectively.

inspected by the Official Veterinary Service. The herd comprised 200 heads, of which 120 were lactating cows. The management conditions and hygienic practices were good, with an average hygienic score of 2 (slightly dirty $2-10 \%$ of surface area; Cook and Reinemann, 2007), especially during milking $(5+5$ herringbone milking parlor where pre- and postdipping with chlorine disinfectants were practiced). The total bacterial count of bulk milk was below $2 \times 10^{4} \mathrm{cfu} / \mathrm{mL}$ for the entire previous year (analyzed by BactoScan FC, Foss, Padua, Italy), with a single exception of $1.1 \times 10^{5} \mathrm{cfu} /$ $\mathrm{mL}$ (Figure 1 ) in the previously mentioned sampling on August 31, 2011.

To find the source of the contamination, on September 19, 2011, individual milk samples from all lactating cows were tested for the excretion of LM through the milk (ISO, 2017a). One cow was positive $\left(9.0 \times 10^{1}\right.$ $\mathrm{cfu} / \mathrm{mL}$ ), although no clinical signs of mastitis were present and a normal SCC of 1.3 to $1.4 \times 10^{5}$ cells $/ \mathrm{mL}$ was recorded (Fossomatic 5000; Foss Electric, Hillerød, Denmark). The positive cow's milk was retested on September 22, 2011, confirming the excretion of LM. Notably, 3 consecutive bulk tank milk samples col- lected on September 22 and 26 and October 4, 2011, excluding the positive cow's milk were negative for LM. Based on these results, the Official Veterinary Service considered the outbreak solved and reauthorized the selling of raw milk through the vending machine, with the exclusion of the positive cow. Antimicrobial susceptibility test by agar disk diffusion method (CLSI, 2013) of the LM isolate revealed sensitivity to first-generation cephalosporins, amoxicillin-clavulanic acid association, trimethoprim-sulfonamide association, tetracyclines, and tylosin and intermediate sensitivity to penicillin. Notably, the result for penicillin was interpreted according to the parameters indicated by CLSI (2013) for Streptococcus spp. because no interpretation data were available for LM.

Upon individual quarter examination of the infected cow (on October 18, 2011, before antimicrobial treatment) by plating milk on blood $(0.01 \mathrm{~mL})$ and agar Listeria according to Ottaviani and Agosti (ALOA) agar (0.1 mL; ISO, 2017b), LM was recovered only in the right anterior quarter, with a load of $2.1 \times 10^{2} \mathrm{cfu} /$ $\mathrm{mL}$. The SCC of the affected quarter was $3.0 \times 10^{5} /$ $\mathrm{mL}$. The cow received local antimicrobial therapy in 
Table 1. Sources and time of isolation of Listeria monocytogenes isolates of the study ${ }^{1}$

\begin{tabular}{lll}
\hline Isolate & Source & $\begin{array}{l}\text { Date of } \\
\text { sampling }\end{array}$ \\
\hline LM1 & Milk from vending machine & Aug. 31, 2011 \\
LM2 & Milk from vending machine & Sep. 8, 2011 \\
LM3 & Tank milk & Sep. 8, 2011 \\
LM4 & Tank milk & Sep. 14, 2011 \\
LM5 & Single-cow milk & Sep. 19, 2011 \\
LM6 & Single-cow milk (typical colony) & Sep. 22, 2011 \\
LM7 & Single-cow milk (atypical colony) & Sep. 22, 2011 \\
LM8 & Single-cow milk after antimicrobial treatment (typical colony) & Oct. 25, 2011 \\
LM9 & Single-cow milk after antimicrobial treatment (atypical colony) & Oct. 25, 2011 \\
LM10 & Udder (specimen A) & Nov. 22, 2011 \\
LM11 & Lymph node (specimen A) & Nov. 22, 2011 \\
LM12 & Udder (specimen B) & Nov. 22, 2011 \\
LM13 & Lymph node (specimen B) & Nov. 22, 2011 \\
\hline
\end{tabular}

${ }^{1}$ Typical and atypical colonies in agar Listeria according to Ottaviani and Agosti (ALOA) agar are defined according to ISO (2017a,b) methods 11290-1 and 11290-2. Typical colonies were blue-green and surrounded by an opaque halo, and atypical colonies were blue-green with no halo.

the infected quarter with a mammary preparation of penicillin-streptomycin association [containing benzopenicillin (600,000 UI/tube) and streptomycin sulfate $(0.5 \mathrm{~g} /$ tube) $]$ administered 3 times for 3 consecutive milking sessions and by a parenteral administration of sulfamethazine-trimethoprim association (containing $25 \mathrm{mg}$ of sulfamethazine and $5 \mathrm{~g}$ of trimethoprim) for 3 d. Sampling was carried out on October 25, 2011, after antimicrobial treatment. The treatment led to a reduction of somatic cells $\left(1.9 \times 10^{4}\right.$ cells $\left./ \mathrm{mL}\right)$, but the excretion of LM remained high $\left(>3.0 \times 10^{2} \mathrm{cfu} / \mathrm{mL}\right)$.

The cow was culled on November 22, 2011, and LM was recovered from the mammary parenchyma of the infected cow and its lymph nodes. The bulk tank milk was further monitored according to the regulatory standards (Supplemental Table S1, https://doi.org/ 10.3168/jds.2019-16267), and no further positive LM samples were detected.

A total of 13 isolates of LM were recovered from different sources (Table 1) over a period of about 3 mo and were subjected to genetic analysis using serogroup PCR (Doumith et al., 2004), pulsed-field gel electrophoresis (CDC, 2017), and whole-genome sequencing (WGS; Illumina MiSeq, Illumina, San Diego, CA) to ascertain the clonality of contamination. All isolates belonged to serogroup IIa, which encompasses both serotypes $1 / 2 \mathrm{a}$ and $3 \mathrm{a}$ (Figure $2 \mathrm{~A}$ ), and all showed the same pulsed-field gel electrophoresis pattern (Figure $2 \mathrm{~B})$. These preliminary results indicated that all isolates were closely related. For this reason, their level of relatedness and genomic characterization were further investigated by WGS. An SNP analysis, performed starting from sequencing reads using CFSAN pipeline version 0.8.0 (Davis et al., 2015), revealed that the 13 isolates formed a tight cluster (with maximum pairwise difference of 4 SNP among the isolates), confirming that they belonged to a single clone. Raw reads of all LM sequenced isolates were submitted to EBI under study accession number PRJEB29442.

Whole-genome sequencing allowed further characterization of the study isolates. In particular, in silico multilocus sequence typing analysis (Pasteur BIGSdbLm database, http://bigsdb.pasteur.fr/listeria/listeria .html) showed that our clone belonged to lineage II, sequence type 37 and clonal complex 37 . This clonal complex has been associated with human listeriosis outbreaks caused by the consumption of contaminated food (Dreyer et al., 2016; Maury et al., 2016) and has been one of the most frequently recovered in a recent study, where LM isolates from milk, milk filters, and milking equipment from different states in the United States were analyzed (Kim et al., 2018). The same study reported that only a small proportion of field isolates $(4 / 121)$ harbored genes associated with antimicrobial resistance (Kim et al., 2018). Notably, this was the case for our 13 isolates that did not possess any alreadyknown antimicrobial resistance genes, as evaluated using the ResFinder database (Zankari et al., 2012). This finding, consistent with the generalized sensitivity detected through the agar disk diffusion test of the study strain, contradicts the unsuccessful outcome of antimicrobial treatment of the infected cow. However, similar failures of antimicrobial treatment had already been reported in other cases of ruminant mastitis by LM (Fedio et al., 1990; Hunt et al., 2012). In this regard, several explanations can be evocated, including the reduced activity of trimethoprim-sulfonamides in milk (Constable et al., 2008) and the poor activity of the penicillin-streptomycin association against an intracellular pathogen such as LM. Moreover, the ability of Listeria spp. in general, and LM in particular, to form biofilm can limit the drug-cell interaction (Os- 
man et al., 2016), further increasing the probability of therapeutic failure.

Investigating the genome of our LM isolates for virulence determinants by the Virulence Factor BigsDB database (Institut Pasteur; http://bigsdb.web.pasteur .fr/listeria/), we detected the presence of genes linked to the virulence of LM (Supplemental Table S2, https: //doi.org/10.3168/jds.2019-16267). In particular, the Listeria pathogenicity island (LIPI)-1 was present, and the gene coding for the InlA protein, a surface invasin known to promote bacterial uptake by host cells, was present in its full-length form as opposed to the truncated form detected in virulence-attenuated sequence types (Jacquet et al., 2004). Other pathogenicityassociated genetic determinants such as LIPI-3, LIPI-4, Listeria genomic island-1, and stress survival islet-1 were absent, as observed for other isolates of sequence type 37 (Kim et al., 2018).

The evidence collected herein shows that contamination of bulk milk by LM can be the consequence of the subclinical infection of just a single quarter of a cow in a herd with good hygienic standards. This finding should serve as a reminder of the insidious nature of the health risk posed by LM, a potentially deadly pathogen for humans. Furthermore, when raw milk is put on the market, there is a need to inform consumers about the health risk and the importance of heattreating raw milk before consumption. In line with the scientific opinion on the public health risks related to the consumption of raw drinking milk of the European Food Safety Authority (EFSA Panel on Biological Hazards, 2015), Italian law obliges the owners of vending machines to inform consumers to boil the milk before its consumption. Moreover, this case has shown that excretion of LM by a clinically healthy cow can last for months, with no benefit from antimicrobial treatment. A further lesson could be learned from the use of highresolution typing methods, namely WGS, which proved to be very helpful in demonstrating the clonal nature of milk contamination over time with unprecedented
A

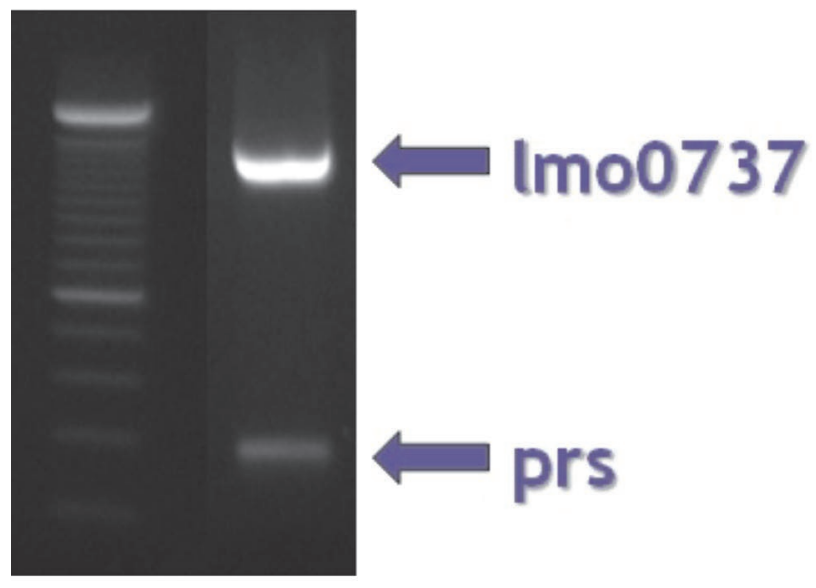

B

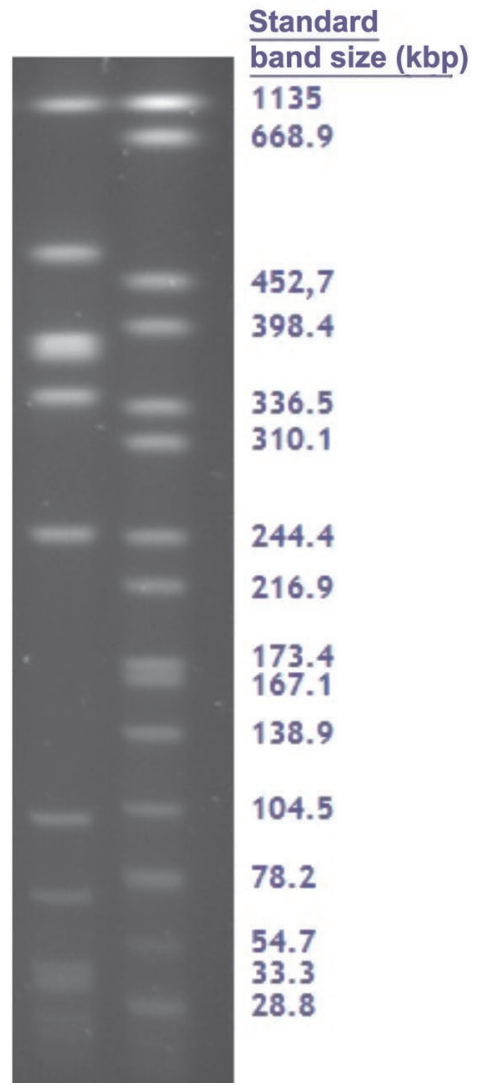

Figure 2. Molecular subtyping to identify Listeria monocytogenes serogroups by multiplex PCR (A) and by pulsed-field gel electrophoresis (B). The characteristic PCR band pattern of serogroup IIa (serotype 1/2a - 3a) is shown in panel A: presence of lmo0737 fragment and prs (Listeria genus-specific gene). The left lane shows SmartLadderSF molecular weight markers (Kaneka Eurogentec S.A., Seraing, Belgium). The pulsed-field gel electrophoresis band pattern with AscI restriction enzyme is shown in panel B (left pattern) along with molecular weight size standard Salmonella Braenderup H9812 XbaI restricted according to CDC (2017; right pattern). 
confidence as well as in identifying virulence factors within the isolates recovered.

\section{REFERENCES}

Bergholz, T. M., M. K. Shah, L. S. Burall, M. Rakic-Martinez, and A. R. Datta. 2018. Genomic and phenotypic diversity of Listeria monocytogenes clonal complexes associated with human listeriosis. Appl. Microbiol. Biotechnol. 102:3475-3485.

Bourry, A., B. Poutrel, and J. Rocourt. 1995. Bovine mastitis caused by Listeria monocytogenes: Characteristics of natural and experimental infections. J. Med. Microbiol. 43:125-132.

CDC (Centers for Disease Control and Prevention). 2017. Standard operating procedure for PulseNet PFGE of Listeria monocytogenes. Accessed Apr. 16, 2019. https://www.cdc.gov/pulsenet/ PDF/listeria-pfge-protocol-508c.pdf.

CLSI (Clinical and Laboratory Standards Institute). 2013. VET01S2: Performance Standards for Antimicrobial Disk and Dilution Susceptibility Tests for Bacteria Isolated from Animals. 2nd ed. CLSI, Wayne, PA.

Constable, P. D., S. Pyörälä, and G. W. Smith. 2008. Guidelines for antimicrobial use in cattle. Pages 143-160 in Guide to Antimicrobial Use in Animals. L. Guardabassi, L. B. Jensen, and H. Kruse, ed. Blackwell, Oxford, UK.

Cook, B. N., and D. Reinemann. 2007. A tool box for assessing cow udder and teat hygiene. Paper presented at the 46th Annual Meeting of the National Mastitis Council.

Davis, S., J. B. Pettengill, Y. Luo, J. Payne, A. Shpuntoff, H. Rand, and E. Strain. 2015. CFSAN SNP Pipeline: An automated method for constructing SNP matrices from next-generation sequence data. Peer.J Comput. Sci. 1:e20.

Doumith, M., C. Buchrieser, P. Glaser, C. Jacquet, and P. Martin. 2004. Differentiation of the major Listeria monocytogenes serovars by multiplex PCR. J. Clin. Microbiol. 42:3819-3822.

Dreyer, M., L. Aguilar-Bultet, S. Rupp, C. Guldimann, R. Stephan, A. Schock, A. Otter, G. Schüpbach, S. Brisse, M. Lecuit, J. Frey, and A. Oevermann. 2016. Listeria monocytogenes sequence type 1 is predominant in ruminant rhombencephalitis. Sci. Rep. 6:36419.

EFSA Panel on Biological Hazards. 2015. Public health risks related to raw drinking milk. EFSA J. 13:3940.

Fedio, W. M., M. Schoonderwoerd, R. H. Shute, and H. Jackson. 1990. A case of bovine mastitis caused by Listeria monocytogenes. Can. Vet. J. 31:773-775

Gasanov, U., D. Hughes, and P. M. Hansbro. 2005. Methods for the isolation and identification of Listeria spp. and Listeria monocytogenes: A review. FEMS Microbiol. Rev. 29:851-875.

Gitter, M., R. Bradley, and P. H. Blampied. 1980. Listeria monocytogenes infection in bovine mastitis. Vet. Rec. 107:390-393.

Harter, E., E. M. Wagner, A. Zaiser, S. Halecker, M. Wagner, and K. Rychli. 2017. Stress survival islet 2, predominantly present in Listeria monocytogenes strains of sequence type 121, is involved in the alkaline and oxidative stress responses. Appl. Environ. Microbiol. 83:e00827-17.

Hunt, K., N. Drummond, M. Murphy, F. Butler, J. Buckley, and K. Jordan. 2012. A case of bovine raw milk contamination with Listeria monocytogenes. Ir. Vet. J. 65:13.
ISO (International Organization for Standardization). 2017a. ISO 11290-1:1996. Microbiology of food and animal feeding stuffs-Horizontal method for the detection and enumeration of Listeria monocytogenes-Part 1: Detection method. ISO, Geneva, Switzerland.

ISO (International Organization for Standardization). 2017b. ISO 11290-2. Microbiology of food and animal feeding stuffs-Horizontal method for the detection and enumeration of Listeria monocytogenes-Part 2: Enumeration method. ISO, Geneva, Switzerland.

Jacquet, C., M. Doumith. J. I. Gordon, P. M. Martin, P. Cossart, and M. Lecuit. 2004. A molecular marker for evaluating the pathogenic potential of foodborne Listeria monocytogenes. J. Infect. Dis. 189:2094-2100.

Katharios-Lanwermeyer, S., M. Rakic-Martinez, D. Elhanafi, S. Ratani, J. M. Tiedje, and S. Kathariou. 2012. Coselection of cadmium and benzalkonium chloride resistance in conjugative transfers from nonpathogenic Listeria spp. to other Listeriae. Appl. Environ. Microbiol. 78:7549-7556.

Kim, S. W., J. Haendiges, E. N. Keller, R. Myers, A. Kim, J. E. Lombard, J. S. Karns, J. A. S. Van Kessel, and B. J. Haley. 2018. Genetic diversity and virulence profiles of Listeria monocytogenes recovered from bulk tank milk, milk filters, and milking equipment from dairies in the United States (2002 to 2014). PLoS One 13:e0197053.

Lee, S., T. J. Ward, D. D. Jima, C. Parsons, and S. Kathariou. 2017. The arsenic resistance-associated Listeria genomic island LGI2 exhibits sequence and integration site diversity and a propensity for three Listeria monocytogenes clones with enhanced virulence. Appl. Environ. Microbiol. 83:e01189-17.

Maury, M. M., Y. H. Tsai, C. Charlier, M. Touchon, V. Chenal-Francisque, A. Leclercq, A. Criscuolo, C. Gaultier, S. Roussel, A. Brisabois, O. Disson, E. P. C. Rocha, S. Brisse, and M. Lecuit. 2016. Uncovering Listeria monocytogenes hypervirulence by harnessing its biodiversity. Nat. Genet. 48:308-313.

NicAogáin, K., and C. P. O'Byrne. 2016. The role of stress and stress adaptations in determining the fate of the bacterial pathogen. Front. Microbiol. 7:1865.

Osman, K. M., A. Samir, U. H. Abo-Shama, E. H. Mohamed, A. Orabi, and T. Zolnikov. 2016. Determination of virulence and antibiotic resistance pattern of biofilm producing Listeria species isolated from retail raw milk. BMC Microbiol. 16:263.

Schoder, D., P. Winter, A. Kareem, W. Baumgartner, and M. Wagner. 2003. A case of sporadic ovine mastitis caused by Listeria monocytogenes and its effect on contamination of raw milk and raw-milk cheeses produced in the on-farm dairy. J. Dairy Res. 70:395-401.

Sharp, M. W. 1989. Bovine mastitis and Listeria monocytogenes. Vet. Rec. 125:512-513.

Winter, P., F. Schilcher, Z. Bago, D. Schoder, M. Egerbacher, W. Baumgartner, and M. Wagner. 2004. Clinical and histopathological aspects of naturally occurring mastitis caused by Listeria monocytogenes in cattle and ewes. J. Vet. Med. B Infect. Dis. Vet. Public Health 51:176-179.

Zankari, E., H. Hasman, S. Cosentino, M. Vestergaard, S. Rasmussen, O. Lund, F. M. Aarestrup, and M. V. Larsen. 2012. Identification of acquired antimicrobial resistance genes. J. Antimicrob. Chemother. 67:2640-2644 